\title{
Anterolateral Ligament of the Knee Shows Variable Anatomy in Pediatric Specimens
}

\author{
Kevin G. Shea MD, Matthew D. Milewski MD, Peter C. Cannamela BS, \\ Theodore J. Ganley MD, Peter D. Fabricant MD, Elizabeth B. Terhune BS, \\ Alexandra C. Styhl BA, Allen F. Anderson MD, John D. Polousky MD
}

Published online: 31 October 2016

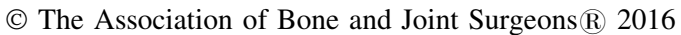

\begin{abstract}
Background Anterior cruciate ligament (ACL) reconstruction failure rates are highest in youth athletes. The role of the anterolateral ligament in rotational knee stability is of increasing interest, and several centers are exploring
\end{abstract}

Each author certifies that he or she, or a member of his or her immediate family, has no funding or commercial associations (eg, consultancies, stock ownership, equity interest, patent/licensing arrangements, etc) that might pose a conflict of interest in connection with the submitted article.

All ICMJE Conflict of Interest Forms for authors and Clinical Orthopaedics and Related Research ${ }^{\mathbb{B}}$ editors and board members are on file with the publication and can be viewed on request.

Clinical Orthopaedics and Related Research ${ }^{\mathbb{R}}$ neither advocates nor endorses the use of any treatment, drug, or device. Readers are encouraged to always seek additional information, including FDAapproval status, of any drug or device prior to clinical use.

Each author certifies that his or her institution approved or waived approval for the human protocol for this investigation and that all investigations were conducted in conformity with ethical principles of research.

This study was performed at St Luke's Hospital, Boise, ID, USA.

K. G. Shea, P. C. Cannamela ( $\square)$

St Luke's Sports Medicine, 600 Robbins Road, Boise, ID 83702,

USA

e-mail: pcannamela@sandiego.edu

M. D. Milewski

Connecticut Children's Medical Center, Hartford, CT, USA

T. J. Ganley

Children's Hospital of Philadelphia, Philadelphia, PA, USA

P. D. Fabricant

Hospital for Special Surgery, New York, NY, USA

E. B. Terhune

Georgetown University School of Medicine, Washington, DC, USA combined ACL and anterolateral ligament reconstruction for these young patients. Literature on the anterolateral ligament of the knee is sparse in regard to the pediatric population. A single study on specimens younger than age 5 years demonstrated the presence of the anterolateral ligament in only one of eight specimens; therefore, much about the prevalence and anatomy of the anterolateral ligament in pediatric specimens remains unknown.

Questions/purposes We sought to (1) investigate the presence or absence of the anterolateral ligament in prepubescent anatomic specimens; (2) describe the anatomic relationship of the anterolateral ligament to the lateral collateral ligament; and (3) describe the anatomic relationship between the anterolateral ligament and the physis. Methods Fourteen skeletally immature knee specimens (median age, 8 years; range, 7-11 years) were dissected (12 male, two female specimens). The posterolateral structures were identified in all specimens, including the lateral collateral ligament and popliteus tendon. The presence or absence of the anterolateral ligament was documented in each

A. C. Styhl

University of Washington School of Medicine, Seattle, WA, USA

\section{A. F. Anderson}

Tennessee Orthopaedic Alliance, Clarksville, TN, USA

J. D. Polousky

Children's Health Specialty Center Plano Campus, Andrews Institute/Children's Health, Plano, TX, USA 
specimen, along with origin, insertion, and dimensions, when applicable. The relationship of the anterolateral ligament origin to the lateral collateral ligament origin was recorded. Results The anterolateral ligament was identified in nine of 14 specimens. The tibial attachment point was consistently located in the same region on the proximal tibia, between the fibular head and Gerdy's tubercle; however, the femoral origin of the anterolateral ligament showed considerable variation with respect to the lateral collateral ligament origin. The median femoral origin of the anterolateral ligament was $10 \mathrm{~mm}$ (first interquartile $6 \mathrm{~mm}$, third interquartile 13) distal to the distal femoral physis, whereas its median insertion was $9 \mathrm{~mm}$ (first interquartile $5 \mathrm{~mm}$, third interquartile $11 \mathrm{~mm}$ ) proximal to the proximal tibial physis. Conclusions The frequency of the anterolateral ligament in pediatric specimens we observed was much lower than other studies on adult specimens; future studies might further investigate the prevalence, development, and functional role of the anterolateral ligament of the knee. Clinical Relevance This study expands our understanding of the anterolateral ligament and provides important anatomic information to surgeons considering anterolateral ligament reconstruction concomitantly with primary or revision ACL reconstruction in pediatric athletes.

\section{Introduction}

Originally identified as a "pearly, fibrous band" by Segond in 1879 [22], the anterolateral ligament of the knee has been recognized as a stabilizing structure thought to resist internal rotation of the tibia for over a century. However, with increasing numbers of young athletes sustaining anterior cruciate ligament (ACL) injury $[7,28]$ and concerns of insufficient rotational stability after ACL reconstruction $[5,15,19,22]$, the anterolateral ligament has garnered increasing interest over the past decade. Recent anatomic and biomechanical studies have investigated the role the anterolateral ligament plays in knee stability [6, 15, 21, 27, 29], and although its contributions are not yet completely understood [14, 23], several surgical techniques have been developed in attempts of restoring normal knee function and kinematics provided by the anterior cruciate and anterolateral structures $[8,13,26]$.

An enhanced understanding of lateral knee anatomy is valuable as the indications for anterolateral ligament repair and reconstruction continue to evolve. Previous studies on adult specimens have agreed it is a consistently present structure in the skeletally mature $[2,6,10,18]$, but have reached varying conclusions on the anatomic origin of the anterolateral ligament in relation to the lateral collateral ligament. Thus, for surgeons who are considering anterolateral ligament reconstruction, it is not clear what constitutes an anatomic reconstruction. Additionally, there is a dearth of research on the anterolateral ligament in pediatric specimens. One small anatomic series in very young specimens (ages 3 months to 10 years) identified the anterolateral ligament in only one of eight available specimens [24], meaning indications for reconstruction in pediatric patients are even more ambiguous than in the adult population.

The purposes of this study were, therefore, to (1) investigate the presence or absence of the anterolateral ligament in prepubescent anatomic specimens; (2) describe the anatomic relationship of the anterolateral ligament to the lateral collateral ligament; and (3) describe the anatomic relationship between the anterolateral ligament and the physis.

\section{Methods and Materials}

Our institutional review board was consulted before the initiation of this study. Because this study included access to cadaveric specimens without any patient identifiers or contact with the family, institutional review board approval was not deemed necessary. The specimens were provided by an allograft harvesting facility, which had received family consent for use of tissue for research purposes (AlloSource, Centennial, CO, USA).

Fourteen skeletally immature knees (12 male and two female; median age, 8 years; range, 7-11 years) were examined by gross dissection with a group of fellowshiptrained orthopaedic surgeons (KGS, PDF, JDP, TJG, MDM, AFA) all with clinical, surgical, and anatomic-dissection experience on knee specimens. The dissections for each specimen were done by groups of two to three surgeons, and each final dissection and marker placement was reviewed and agreed on by the entire group of surgeons. After anterolateral ligament identification, metallic pins were placed at the center of each ligament origin. Anterolateral ligament dimensions were directly measured both at the time of dissection and by photographs with a ruler in the field. CT scans with 2-mm slices were subsequently taken using a GE (Cincinnati, OH, USA) Litespeed 16-slice scanner to evaluate the precise femoral origin and tibial insertion of the anterolateral ligament in each specimen.

Images were analyzed by two of the authors (KGS, PCC) using OsiriX (Bern, Switzerland) imaging software (Version 6.5.2).

Distance to the femoral and tibial physes was measured in the coronal plane. Using the image in which the metallic marker of the anterolateral ligament attachment was visible, the distance from the lateral aspect of the physis to the anterolateral ligament attachment was measured. This was 
done for both the femoral and tibial attachments of the anterolateral ligament.

In the sagittal plane, the location of each pin (on the lateral surface of the femoral condyle) was marked and images from the same CT scan series were overlaid. This produced a single image in which the widest portion of the femoral condyle, the posterior cortical line, and pin locations were all visible (Fig. 1). This generated a simulated intraoperative lateral fluoroscopic view frequently used by surgeons to localize and confirm placement of surgically reconstructed ligaments. This sequence was repeated for all 14 specimens.

Location of the anterolateral ligament and lateral collateral ligament femoral origins was measured in the sagittal plane as follows:

- Percent AP measurements were obtained by measuring across the lateral femoral condyle perpendicular to the posterior cortical line. First, the total AP distance (depth) of the lateral femoral condyle was measured. Then the distance from the ligament origin (either anterolateral ligament or lateral collateral ligament) to the most posterior aspect of the lateral femoral condyle was measured, and percent AP value was calculated by dividing this value by the total depth of the respective condyle and multiplying by 100 (Fig. 2). A

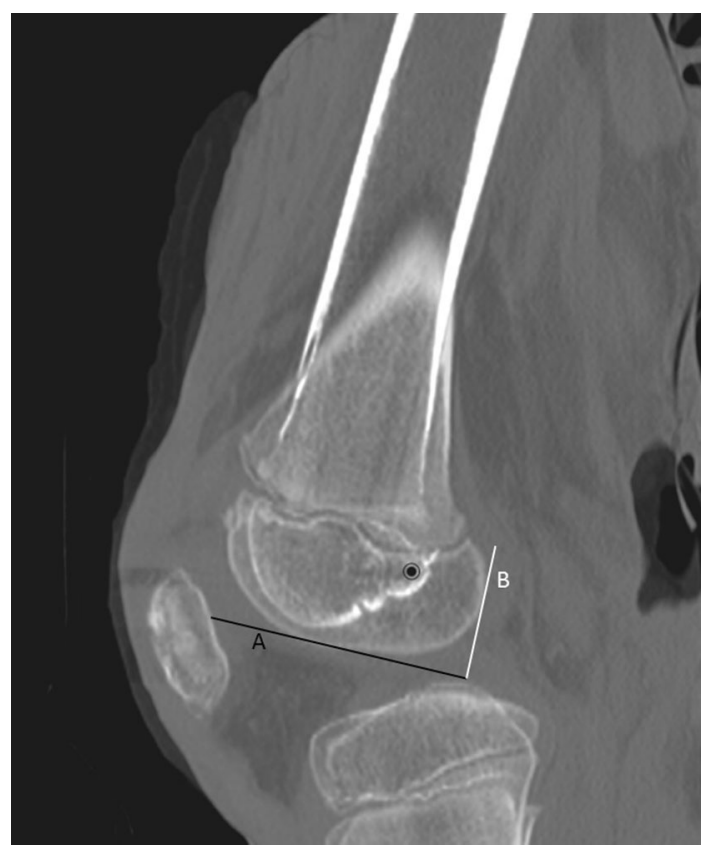

Fig. 1 The figure shows merged CT images to replicate the view available by intraoperative fluoroscopy. A digital marker (black bull's eye) has been drawn over the signal produced by the metallic pin. Line A represents the condylar depth; Line B represents the condylar height. Line B extends perpendicularly from Line A at the most posterior aspect of the femoral condyle to the most proximal aspect of the posterior physis. measurement of $0 \%$ AP would thus correspond to a ligament origin at the most posterior aspect of the condyle, whereas an origin measuring $100 \%$ AP would be at the anterior most aspect of the femoral condyle.

- Percent proximal-distal measurements were obtained by measuring the proximal distal distance (height) of the lateral femoral condyle parallel to the posterior cortical line. The height of the condyle was measured from the most proximal point of the posterior aspect of the physis to the most distal aspect of the lateral femoral condyle. This posterior point of the physis was selected, because it was one of the most consistent landmarks on these images. Distance from the ligament origin to the most proximal, posterior aspect of the physis was then measured, divided by the height of its respective condyle, and multiplied by 100 to yield a percent proximal distal (Fig. 3). A measurement of $0 \%$ proximal distal corresponds to a point at the distal femoral physis, whereas a measurement of $100 \%$ proximal distal corresponds to a point at the most distal aspect of the condyle.

- Lateral femoral condyle ossified condylar areas were calculated by multiplying the measured lateral femoral condyle depth by the corresponding lateral femoral condyle height (see measurements in Fig. 1). This was performed to quantify the size and development of each pediatric knee specimen and allow for reporting of normalized results.

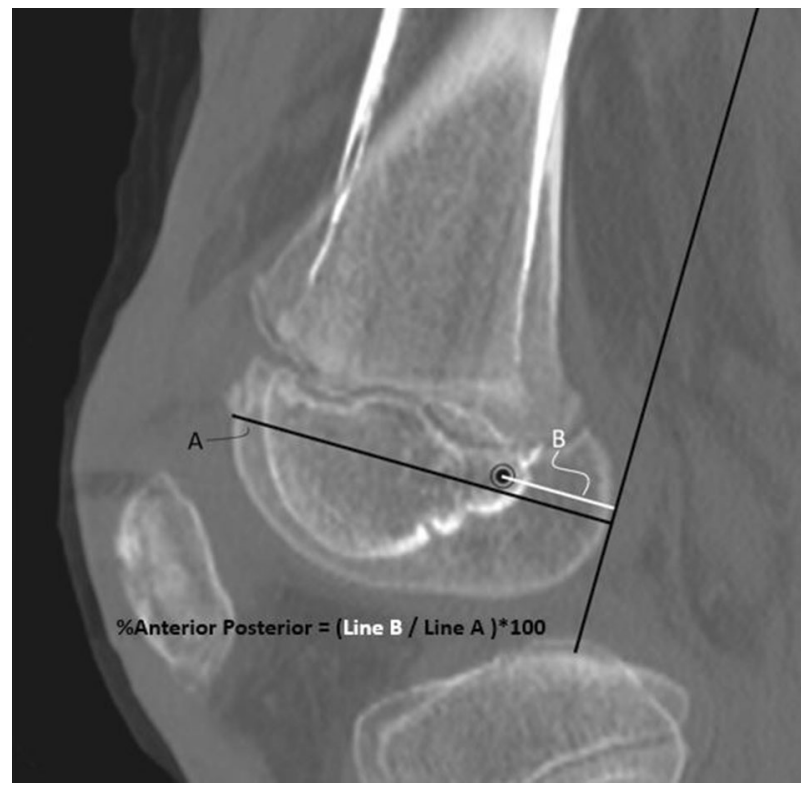

Fig. 2 Line A shows the total depth of the lateral femoral condyle. Line B shows the distance from a ligament origin to the most posterior aspect of the lateral femoral condyle. Length of Line B was divided by the length of Line A and multiplied by 100 to determine $\%$ AP. Point shown in figure measures approximately $30 \%$ AP. 


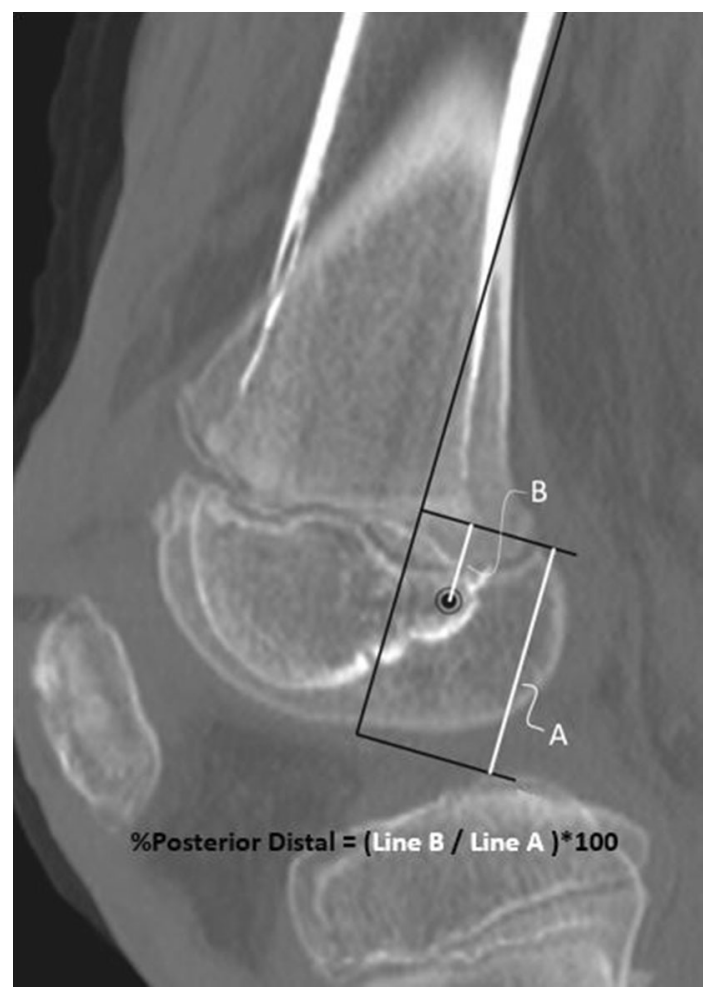

Fig. 3 Line A shows the total height of the lateral femoral condyle. Line B shows the distance from the ligament origin to the posterosuperior aspect of the lateral femoral condyle. Height of Line B was divided by the height of Line A and multiplied by 100 to determine $\%$ proximal distal. Point shown in figure measures approximately $30 \%$ proximal distal

\section{Results}

Of the 14 knee specimens in the study, nine were found to have an anterolateral ligament. When sorted by ossified condylar area and dichotomized, an anterolateral ligament was identified in all seven of the knees in the larger half of specimens, whereas only two of seven knees in the smaller half of specimens had an identifiable anterolateral ligament (Table 1). The identified ligaments varied in appearance, ranging from a thin, sheet-like structure in some specimens to a well-defined "pearly band" in others (Fig. 4). AP measurements resulted in a median of $33 \%$ (first interquartile $29 \%$, third interquartile $35 \%$ ) AP for the anterolateral ligament origin midpoint (Table 2) and 29\% (first interquartile $25 \%$, third interquartile $31 \%$ ) for the lateral collateral ligament origin (Table 3). Proximal distal measurements resulted in medians of $43 \%$ (first interquartile $23 \%$, third interquartile $47 \%$ ) proximal distal for the anterolateral ligament origin (Table 4) and 37\% (first interquartile 36\%, third interquartile $43 \%$ ) for the lateral collateral ligament origin (Table 5).

The location of the anterolateral ligament origin in relation to the lateral collateral ligament markedly varied
Table 1. Specimens listed in order of size of specimen, as determined by the ossified condylar area $\left(\mathrm{mm}^{2}\right)$ measured in the sagittal plane

\begin{tabular}{llllll}
\hline $\begin{array}{l}\text { Specimen } \\
\text { number }\end{array}$ & $\begin{array}{l}\text { Ossified } \\
\text { condylar } \\
\text { area }\left(\mathrm{mm}^{2}\right)\end{array}$ & $\begin{array}{l}\text { Specimen } \\
\text { age } \\
\text { (years) }\end{array}$ & $\begin{array}{l}\text { Anterolateral } \\
\text { ligament } \\
\text { present? }\end{array}$ & Laterality & Sex \\
\hline 1 & 540 & 7 & & $\mathrm{~L}$ & $\mathrm{~F}$ \\
2 & 540 & 7 & & $\mathrm{R}$ & $\mathrm{F}$ \\
3 & 750 & 7 & $\mathrm{X}$ & $\mathrm{R}$ & $\mathrm{M}$ \\
4 & 800 & 7 & $\mathrm{X}$ & $\mathrm{L}$ & $\mathrm{M}$ \\
5 & 950 & 8 & & $\mathrm{R}$ & $\mathrm{M}$ \\
6 & 1010 & 8 & & $\mathrm{~L}$ & $\mathrm{M}$ \\
7 & 1070 & 11 & & $\mathrm{~L}$ & $\mathrm{M}$ \\
8 & 1140 & 11 & $\mathrm{X}$ & $\mathrm{R}$ & $\mathrm{M}$ \\
9 & 1160 & 8 & $\mathrm{X}$ & $\mathrm{L}$ & $\mathrm{M}$ \\
10 & 1180 & 8 & $\mathrm{X}$ & $\mathrm{R}$ & $\mathrm{M}$ \\
11 & 1290 & 10 & $\mathrm{X}$ & $\mathrm{R}$ & $\mathrm{M}$ \\
12 & 1360 & 10 & $\mathrm{X}$ & $\mathrm{L}$ & $\mathrm{M}$ \\
13 & 1440 & 11 & $\mathrm{X}$ & $\mathrm{L}$ & $\mathrm{M}$ \\
14 & 1510 & 11 & $\mathrm{X}$ & $\mathrm{R}$ & $\mathrm{M}$ \\
\hline
\end{tabular}

Anterolateral ligaments were found in nine of 14 knee specimens: the smaller group of specimens (upper half of table) demonstrated the anterolateral ligament in two of seven specimens; the larger group of specimens (lower half of table) demonstrated the anterolateral ligament in seven of seven specimens; $L=$ left; $R=$ right; $F=$ female; $\mathrm{M}=$ male.

(Figs. 5, 6). Three anterolateral ligament origins were located distal and anterior from their respective lateral collateral ligament origins. In two specimens the anterolateral ligament and lateral collateral ligament shared the same origin location. Two anterolateral ligament origins were proximal and posterior to their lateral collateral ligament origins, one anterolateral ligament was anterior to the lateral collateral ligament, and one anterolateral ligament was proximal and anterior to its lateral collateral ligament origin.

The median anterolateral ligament femoral origin was $10 \mathrm{~mm}$ (first interquartile $6 \mathrm{~mm}$, third interquartile $13 \mathrm{~mm}$ ) distal to the femoral physis, whereas the median tibial insertion was found to be $9 \mathrm{~mm}$ (first interquartile $5 \mathrm{~mm}$, third interquartile $11 \mathrm{~mm}$ ) proximal to the tibial physis (Table 6). The median length of the anterolateral ligament was $33 \mathrm{~mm}$ (first interquartile $31 \mathrm{~mm}$, third interquartile 36 $\mathrm{mm})$. The median width at the femoral origin point was 3 $\mathrm{mm}$ (first interquartile $2 \mathrm{~mm}$, third interquartile $4 \mathrm{~mm}$ ), and the median width at the tibial insertion point was $4 \mathrm{~mm}$ (first interquartile $3 \mathrm{~mm}$, third interquartile $6 \mathrm{~mm}$ ).

\section{Discussion}

The anterolateral ligament has been demonstrated to be a rotational stabilizer of the knee $[15,29]$ and several recent 


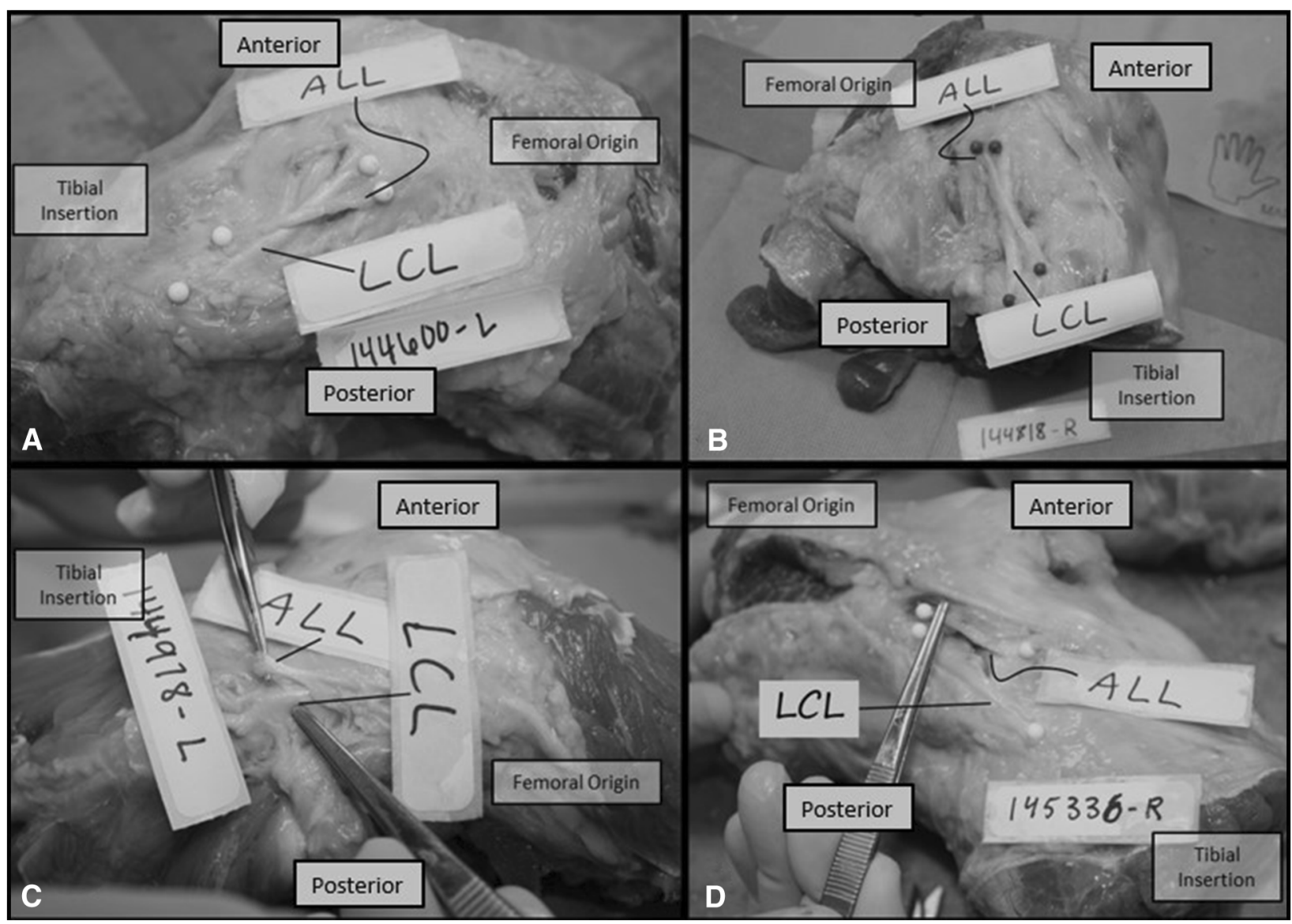

Fig. 4A-D The figure demonstrates that the structural appearance of the anterolateral ligament (ALL) varied in pediatric specimens. (A) Left knee, 8-year-old boy; anterolateral ligament origin is proximal and posterior to the lateral collateral ligament (LCL) origin. The femoral attachment points of the lateral collateral ligament and anterolateral ligament are on the right in this photograph. (B) Right knee, 11-year-old boy; anterolateral ligament origin is proximal and posterior to the lateral collateral ligament. The femoral attachments of the lateral collateral ligament and anterolateral ligament are in the upper region of the photo. (C) Left knee, 10-year-old boy; anterolateral ligament and lateral collateral ligament share the same origin. The femoral attachment point of the lateral collateral ligament and anterolateral ligament are on the right in this photograph. (D) Right knee, 11-year-old boy; anterolateral ligament origin is proximal and anterior to the lateral collateral ligament. The femoral attachments of the lateral collateral ligament and anterolateral ligament are in the upper left region of the photograph.

however, access to pediatric specimens is severely limited. Access to older specimens and additional female specimens, including those closer to skeletal maturity, would also improve the study and provide more information about the development of these structures in older patients. Having multiple surgeons performing the dissections may increase the variation in anatomic identification of structures. To mitigate this bias, each dissection was reviewed by the group of surgeons to confirm dissected structures and placement of markers at specific landmarks.

In contrast to a previous study of very young (age 3 months to 10 years) pediatric knee specimens, which identified the anterolateral ligament in only one of eight [23], this series demonstrated the presence of an anterolateral ligament in nine of 14 specimens. This series was an 
Table 2. Anterolateral ligament AP measurements were performed in the sagittal plane

\begin{tabular}{llll}
\hline $\begin{array}{l}\text { Specimen } \\
\text { number }\end{array}$ & $\begin{array}{l}\text { Lateral femoral } \\
\text { condyle depth }(\mathrm{mm})\end{array}$ & $\begin{array}{l}\text { Anterolateral ligament origin } \\
\text { to posterior condyle }(\mathrm{mm})\end{array}$ & $\begin{array}{l}\% \\
\text { AP }\end{array}$ \\
\hline 3 & 37 & 19 & 51 \\
4 & 40 & 14 & 35 \\
8 & 48 & 14 & 29 \\
9 & 47 & 10 & 20 \\
10 & 46 & 14 & 30 \\
11 & 49 & 16 & 33 \\
12 & 50 & 14 & 28 \\
13 & 52 & 17 & 33 \\
14 & 53 & 18 & 35 \\
Median & 48 & 14 & 33 \\
Q1 & 46 & 14 & 29 \\
Q3 & 50 & 17 & 35 \\
\hline
\end{tabular}

$\% \mathrm{AP}$ is equal to the distance from the posterior aspect of the femoral condyle to the anterolateral ligament origin divided by the total AP distance of the condyle multiplied by 100 .

Table 3. Lateral collateral ligament AP measurements were performed in the sagittal plane

\begin{tabular}{llll}
\hline $\begin{array}{l}\text { Specimen } \\
\text { number }\end{array}$ & $\begin{array}{l}\text { Lateral femoral } \\
\text { condyle depth } \\
(\mathrm{mm})\end{array}$ & $\begin{array}{l}\text { Lateral collateral ligament } \\
\text { origin to posterior condyle } \\
(\mathrm{mm})\end{array}$ & $\begin{array}{l}\% \\
\text { AP }\end{array}$ \\
\hline 1 & 33 & 9 & 28 \\
2 & 33 & 4 & 12 \\
3 & 37 & 11 & 29 \\
4 & 40 & 13 & 32 \\
5 & 42 & 12 & 29 \\
6 & 44 & 10 & 22 \\
7 & 46 & 15 & 31 \\
8 & 48 & 13 & 27 \\
9 & 47 & 15 & 31 \\
10 & 46 & 15 & 33 \\
11 & 49 & 16 & 33 \\
12 & 50 & 14 & 28 \\
13 & 52 & 12 & 24 \\
14 & 53 & 13 & 24 \\
Median & 46 & 13 & 29 \\
Q1 & 41 & 11 & 25 \\
Q3 & 49 & 15 & 31 \\
\hline$\%$ AP & & &
\end{tabular}

$\% \mathrm{AP}$ is equal to the distance from the posterior aspect of the femoral condyle to the lateral collateral ligament origin divided by the total AP distance of the condyle multiplied by 100 .

older group of specimens, suggesting that the ligament may become more distinct as it develops over time. Although some recent studies have found the anterolateral ligament in less than $50 \%$ of specimens $[17,20,21]$, adult cadaveric studies have generally shown it to be present in a much
Table 4. Measurements were done in the sagittal plane

\begin{tabular}{llll}
\hline $\begin{array}{l}\text { Specimen } \\
\text { number }\end{array}$ & $\begin{array}{l}\text { Epiphysis } \\
\text { height }(\mathrm{mm})\end{array}$ & $\begin{array}{l}\text { Anterolateral ligament } \\
\text { origin to physis }(\mathrm{mm})\end{array}$ & $\begin{array}{l}\% \\
\text { Proximal } \\
\text { distal }\end{array}$ \\
\hline 3 & 20 & 13 & 63 \\
4 & 20 & 9 & 47 \\
8 & 24 & 3 & 11 \\
9 & 25 & 4 & 16 \\
10 & 26 & 6 & 23 \\
11 & 27 & 10 & 36 \\
12 & 28 & 12 & 43 \\
13 & 28 & 15 & 55 \\
14 & 29 & 13 & 44 \\
Median & 26 & 10 & 43 \\
Q1 & 24 & 6 & 23 \\
Q3 & 28 & 13 & 47
\end{tabular}

$\%$ Proximal distal is equal to the distance from the proximal aspect of the femoral epiphysis to the anterolateral ligament origin divided by the total height of the epiphysis multiplied by 100 .

Table 5. Measurements shown in the table were done in the sagittal plane

\begin{tabular}{llrl}
\hline $\begin{array}{l}\text { Specimen } \\
\text { number }\end{array}$ & $\begin{array}{l}\text { Epiphysis } \\
\text { height }(\mathrm{mm})\end{array}$ & $\begin{array}{l}\text { Lateral collateral ligament } \\
\text { origin to posterior physis }(\mathrm{mm})\end{array}$ & $\begin{array}{l}\% \\
\text { Proximal } \\
\text { distal }\end{array}$ \\
\hline 1 & 25 & 9 & 36 \\
2 & 23 & 8 & 36 \\
3 & 20 & 6 & 27 \\
4 & 28 & 12 & 43 \\
5 & 20 & 7 & 36 \\
6 & 17 & 5 & 30 \\
7 & 26 & 11 & 41 \\
8 & 27 & 10 & 36 \\
9 & 16 & 8 & 47 \\
10 & 23 & 10 & 43 \\
11 & 23 & 7 & 28 \\
12 & 28 & 11 & 39 \\
13 & 24 & 9 & 38 \\
14 & 29 & 13 & 45 \\
Median & 24 & 9 & 37 \\
Q1 & 21 & 7 & 36 \\
Q3 & 27 & 10 & 43 \\
\hline$\%$ Pr & &
\end{tabular}

$\%$ Proximal distal is equal to the distance from the proximal aspect of the femoral epiphysis to the anterolateral ligament origin divided by the total height of the epiphysis multiplied by 100 .

higher percentage of specimens; Dodds et al. [6] identified the anterolateral ligament in 33 of 40 specimens $(83 \%)$, Claes et al. [2] in 40 of 41 specimens (98\%), Vincent et al. [31] in 40 of 40 specimens (100\%), and Daggett et al. [3] in 52 of 52 specimens $(100 \%)$. Most studies agree that the 

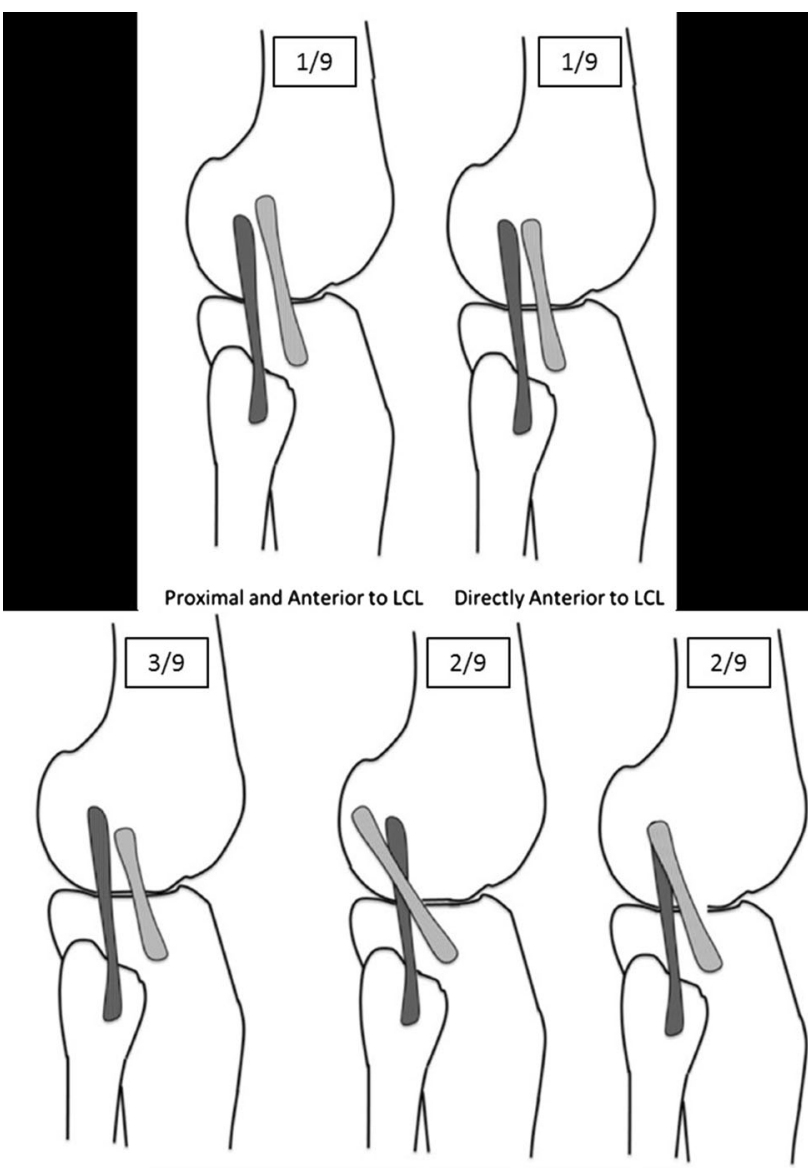

Distal and Anterior to LCL

Proximal and Posterior to $\mathrm{LCL}$

Fig. 5 Variations observed in the relationship between the lateral collateral ligament (LCL) and anterolateral ligament in nine pediatric knee specimens are shown in the figure. The anterolateral ligament was proximal and anterior to the lateral collateral ligament in one specimen, directly anterior to the lateral collateral ligament in one, distal and anterior to the lateral collateral ligament in three, proximal and posterior to the lateral collateral ligament in two, and shared the same origin as the lateral collateral ligament in two.

tibial insertion of the anterolateral ligament can consistently be found approximately halfway between the Gerdy tubercle and the anterior margin of the fibular head $[1,2,6,9,10,18,31]$. However, there have been conflicting reports on the anatomy of its femoral origin $[2,6,18,20]$ and debate on its relative importance in knee stability and kinematics [11, 15, 17, 21]. Although rarely reported and difficult to quantify, the structure of the anterolateral ligament also seems to vary [4] with some studies and dissection photographs showing a thin "sheetlike" structure $[3,6,16]$ and others appearing as more of a thick band $[2,5,20]$. When ordered according to ossified condylar area, the anterolateral ligament was identified in all seven of the larger specimens, but only two of the seven smaller specimens. Taken together with the understanding that the anterolateral ligament appears to be present in the

vast majority of adult specimens [30], the anterolateral ligament may be a structure that develops throughout the prepubertal period.

The current study demonstrated considerable variation in the location of the anterolateral ligament origin with respect to the lateral collateral ligament origin. With respect to the lateral collateral ligament origin, these specimens showed that the anterolateral ligament originated in several different patterns including (1) distal and anterior to the lateral collateral ligament origin; (2) common anterolateral ligament and lateral collateral ligament origin; (3) proximal and posterior to the lateral collateral ligament origins; (4) anterior to the lateral collateral ligament; and (5) proximal and anterior to its lateral collateral ligament origin. This variation has also been identified in adult cadaveric studies with Claes et al. [2] identifying the anterolateral ligament origin as anterior to the lateral collateral ligament origin and Dodds et al. [6] localizing the anterolateral ligament origin as proximal and posterior to the lateral collateral ligament origin. Rezansoff et al. [18] described two anatomic variants-one anterior-distal to the lateral collateral ligament and one posterior-proximal to the lateral collateral ligament-in a study of 13 knees, whereas Runer et al. [20] also described two variants-one proximal and posterior to the lateral collateral ligament origin and one sharing the lateral collateral ligament origin. In the current study, the authors found the anterolateral ligament to be an inconsistent structure with regard to its presence, structure, and its femoral origin in prepubescent pediatric knee specimens. Given that multiple femoral origins have been reported in the adult literature, it seems likely that the anatomic relationship of the lateral collateral ligament and anterolateral ligament might vary as was found in our study of pediatric specimens.

The anterolateral ligament origin showed a close relationship to the femoral physis (median $10 \mathrm{~mm}$ distal) as did the anterolateral ligament insertion to the tibial physis (median $9 \mathrm{~mm}$ proximal). Surgeons considering anterolateral ligament reconstruction in prepubescent patients should be aware of this anatomic relationship. Physicians should be especially careful of causing iatrogenic damage to the distal femoral physis because its undulating structure may confound its relation to the anterolateral ligament origin and ligament reconstructions have the potential to cause growth disturbance [12, 25].

Recently, the anterolateral ligament's status as a true ligament and furthermore its clinical relevance has been called into question [14, 23]; therefore, continued research on the development, structure, and function of the anterolateral ligament in children is needed to further clarify the anatomic role and indications, if any, for combined ACL/ anterolateral ligament reconstructions in young athletes. This study expands our understanding of the anterolateral 
Fig. 6 Lateral collateral ligament (LCL) and anterolateral ligament (ALL) origin distribution as \% AP and \% proximal distal. Lateral collateral ligament origins of specimens without an anterolateral ligament are not shown in the figure. Points are labeled with specimen numbers.

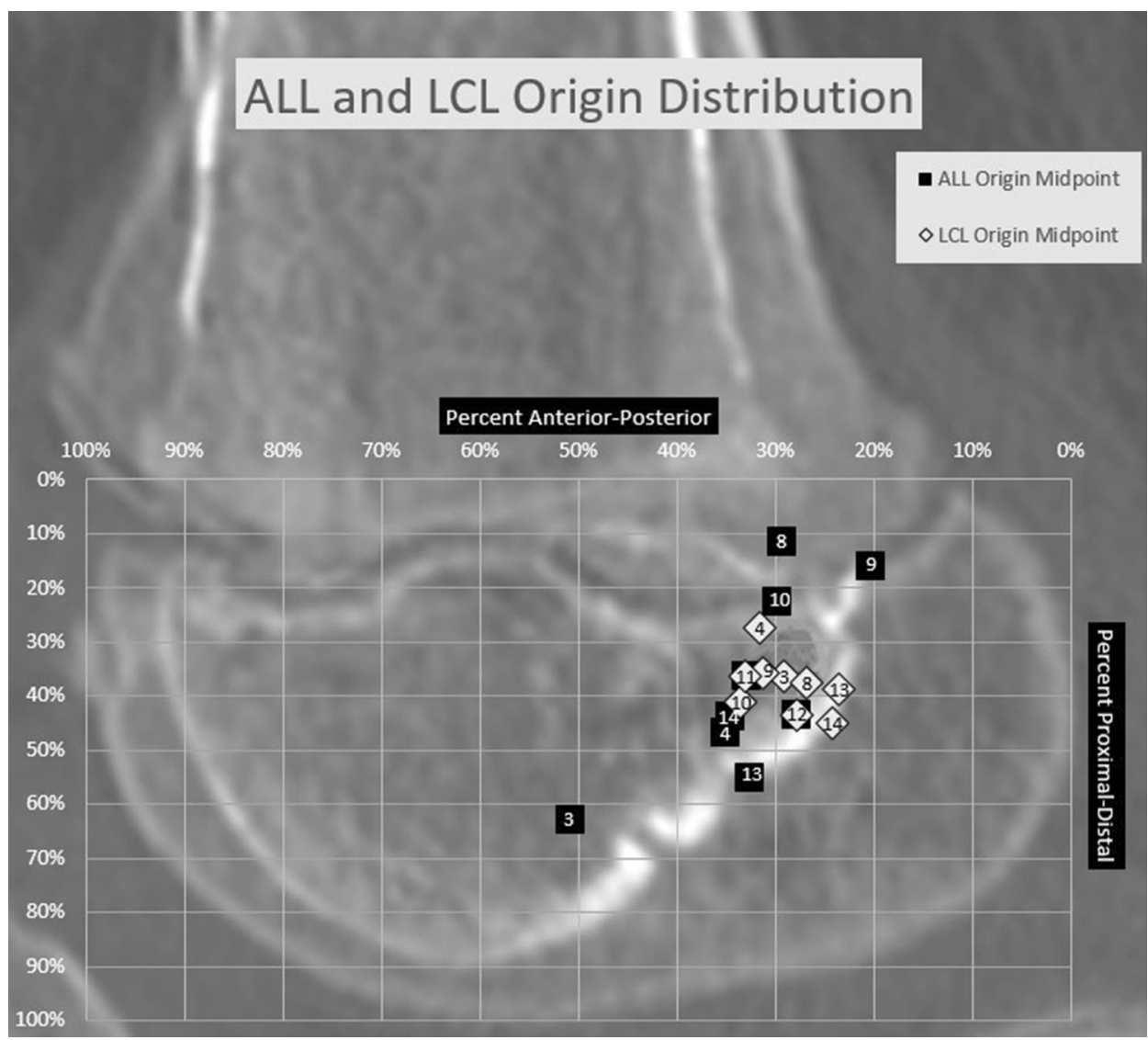

Table 6. Anterolateral ligament dimensions and relationship to physes measurements

\begin{tabular}{|c|c|c|c|c|c|}
\hline $\begin{array}{l}\text { Specimen } \\
\text { number }\end{array}$ & $\begin{array}{l}\text { Anterolateral ligament } \\
\text { length }(\mathrm{mm})\end{array}$ & $\begin{array}{l}\text { Width of tibial } \\
\text { insertion }(\mathrm{mm})\end{array}$ & $\begin{array}{l}\text { Width of femoral } \\
\text { insertion }(\mathrm{mm})\end{array}$ & $\begin{array}{l}\text { Distal to femoral } \\
\text { physis }(\mathrm{mm})\end{array}$ & $\begin{array}{l}\text { Proximal to tibial } \\
\text { physis }(\mathrm{mm})\end{array}$ \\
\hline 3 & 26 & 3 & 4 & 13 & N/A \\
\hline 4 & 31 & 3 & 3 & 9 & 5 \\
\hline 8 & 42 & 4 & 2 & 3 & 0 \\
\hline 9 & 36 & 2 & 2 & 4 & 4 \\
\hline 10 & 34 & 7 & 3 & 6 & 11 \\
\hline 11 & 36 & 3 & 2 & 10 & 10 \\
\hline 12 & 31 & 4 & 3 & 12 & 8 \\
\hline 13 & 29 & 6 & 7 & 15 & 12 \\
\hline 14 & 32 & 6 & 5 & 13 & 13 \\
\hline Median & 32 & 4 & 3 & 10 & 9 \\
\hline Q1 & 31 & 3 & 2 & 6 & 5 \\
\hline Q3 & 36 & 6 & 4 & 13 & 11 \\
\hline
\end{tabular}

Dimensions of the anterolateral ligament were measured during dissections and by photographs with a ruler in the field; distance to the femoral and tibial physes was measured in the coronal plane; using the image in which the metallic marker of the anterolateral ligament attachments was visible, the distance from the lateral aspect of the physis to the anterolateral ligament attachment was measured; this was done for both the femoral and tibial attachments of the anterolateral ligament; no tibial pin was placed for the anterolateral ligament of Specimen 3; N/A = no pin was placed in this specimen. 
ligament and provides important anatomic information to surgeons considering anterolateral ligament reconstruction concomitantly with primary or revision ACL reconstruction in pediatric athletes.

Acknowledgments We thank Allosource (Centennial, CO, USA) for the donation of the cadaveric specimens and nonfinancial research support. We also thank Tom Cycyota and Todd Huft (AlloSource) for their assistance, organization, and support of the dissections.

\section{References}

1. Caterine S, Litchfield R, Johnson M, Chronik B, Getgood A. A cadaveric study of the anterolateral ligament: re-introducing the lateral capsular ligament. Knee Surg Sports Traumatol Arthrosc. 2015;23:3186-3195.

2. Claes S, Vereecke E, Maes M, Victor J, Verdonk P, Bellemans J. Anatomy of the anterolateral ligament of the knee. J Anat. 2013;223:321-328

3. Daggett M, Ockuly AC, Cullen M, Busch K, Lutz C, Imbert P, Sonnery-Cottet B. Femoral origin of the anterolateral ligament: an anatomic analysis. Arthroscopy. 2016;32:835-841.

4. De Maeseneer M, Shahabpour M, Vanderdood K, De Ridder F, Van Roy F, Osteaux M. Posterolateral supporting structures of the knee: findings on anatomic dissection, anatomic slices and MR images. Eur Radiol. 2001;11:2170-2177.

5. Dodds AL, Gupte CM, Neyret P, Williams AM, Amis AA. Extraarticular techniques in anterior cruciate ligament reconstruction: a literature review. J Bone Joint Surg Br. 2011;93:1440-1448.

6. Dodds AL, Halewood C, Gupte CM, Williams A, Amis AA. The anterolateral ligament: Anatomy, length changes and association with the Segond fracture. Bone Joint J. 2014;96:325-331.

7. Dodwell ER, Lamont LE, Green DW, Pan TJ, Marx RG, Lyman S. 20 years of pediatric anterior cruciate ligament reconstruction in New York State. Am J Sports Med. 2014;42:675-680.

8. Helito CP, Bonadio MB, Gobbi RG, da Mota EARF, Pecora JR, Camanho GL, Demange MK. Combined intra- and extra-articular reconstruction of the anterior cruciate ligament: the reconstruction of the knee anterolateral ligament. Arthrosc Tech. 2015;4:e239-244

9. Helito CP, Demange MK, Bonadio MB, Tirico LEP, Gobbi RG, Pecora JR, Camanho GL. Radiographic landmarks for locating the femoral origin and tibial insertion of the knee anterolateral ligament. Am J Sports Med. 2014;42:2356-2362.

10. Kennedy MI, Claes S, Fuso FA, Williams BT, Goldsmith MT, Turnbull TL, Wijdicks CA, LaPrade RF. The anterolateral ligament: an anatomic, radiographic, and biomechanical analysis. Am J Sports Med. 2015;43:1606-1615.

11. Kittl C, El-Daou H, Athwal KK, Gupte CM, Weiler A, Williams A, Amis AA. The role of the anterolateral structures and the ACL in controlling laxity of the intact and ACL-deficient knee. Am J Sports Med. 2016;44:345-354.

12. Lawrence JTR, West RL, Garrett WE. Growth disturbance following ACL reconstruction with use of an epiphyseal femoral tunnel: a case report. J Bone Joint Surg Am. 2011;93:e39 31-36.

13. Monaco E, Labianca L, Conteduca F, De Carli A, Ferretti A. Double bundle or single bundle plus extraarticular tenodesis in ACL reconstruction? A CAOS study. Knee Surg Sports Traumatol Arthrosc. 2007;15:1168-1174.

14. Musahl V, Rahnemai-Azar AA, van Eck CF, Guenther D, Fu FH. Anterolateral ligament of the knee, fact or fiction? Knee Surg Sports Traumatol Arthrosc. 2016;24:2-3.
15. Parsons EM, Gee AO, Spiekerman C, Cavanagh PR. The biomechanical function of the anterolateral ligament of the knee. Am J Sports Med. 2015;43:669-674.

16. Porrino J Jr, Maloney E, Richardson M, Mulcahy H, Ha A, Chew FS. The anterolateral ligament of the knee: MRI appearance, association with the Segond fracture, and historical perspective. AJR Am J Roentgenol. 2015;204:367-373.

17. Rahnemai-Azar AA, Miller RM, Guenther D, Fu FH, Lesniak BP, Musahl V, Debski RE. Structural properties of the anterolateral capsule and iliotibial band of the knee. Am J Sports Med. 2016;44:892-897.

18. Rezansoff AJ, Caterine S, Spencer L, Tran MN, Litchfield RB, Getgood AM. Radiographic landmarks for surgical reconstruction of the anterolateral ligament of the knee. Knee Surg Sports Traumatol Arthrosc. 2015;23:3196-3201.

19. Rezende FC, de Moraes VY, Martimbianco AL, Luzo MV, da Silveira Franciozi CE, Belloti JC. Does combined intra- and extraarticular ACL reconstruction improve function and stability? A meta-analysis. Clin Orthop Relat Res. 2015;473:2609-2618.

20. Runer A, Birkmaier S, Pamminger M, Reider S, Herbst E, Kunzel $\mathrm{KH}$, Brenner E, Fink C. The anterolateral ligament of the knee: A dissection study. Knee. 2016;23:8-12.

21. Saiegh YA, Suero EM, Guenther D, Hawi N, Decker S, Krettek C, Citak M, Omar M. Sectioning the anterolateral ligament did not increase tibiofemoral translation or rotation in an ACL-deficient cadaveric model. Knee Surg Sports Traumatol Arthrosc. 2015 Sep 16. [Epub ahead of print]

22. Samuelson M, Draganich LF, Zhou X, Krumins P, Reider B. The effects of knee reconstruction on combined anterior cruciate ligament and anterolateral capsular deficiencies. Am J Sports Med. 1996;24:492-497.

23. Schon JM, Moatshe G, Brady AW, Serra Cruz R, Chahla J, Dornan GJ, Turnbull TL, Engebretsen L, LaPrade RF. Anatomic anterolateral ligament reconstruction of the knee leads to overconstraint at any fixation angle. Am J Sports Med. 2016;44:2546-2556.

24. Shea KG, Polousky JD, Jacobs JC Jr, Yen Y-M, Ganley TJ. The anterolateral ligament of the knee: an inconsistent finding in pediatric cadaveric specimens. J Pediatr Orthop. 2016;36:e51-54.

25. Shifflett GD, Green DW, Widmann RF, Marx RG. Growth arrest following ACL reconstruction with hamstring autograft in skeletally immature patients: a review of 4 cases. J Pediatr Orthop. 2016;36:355-361.

26. Sonnery-Cottet B, Thaunat M, Freychet B, Pupim BH, Murphy $\mathrm{CG}$, Claes S. Outcome of a combined anterior cruciate ligament and anterolateral ligament reconstruction technique with a minimum 2-year follow-up. Am J Sports Med. 2015;43:1598-1605.

27. Spencer L, Burkhart TA, Tran MN, Rezansoff AJ, Deo S, Caterine S, Getgood AM. Biomechanical analysis of simulated clinical testing and reconstruction of the anterolateral ligament of the knee. Am J Sports Med. 2015;43:2189-2197.

28. Swenson DM, Collins CL, Best TM, Flanigan DC, Fields SK, Comstock RD. Epidemiology of knee injuries among US high school athletes, 2005/2006-2010/2011. Med Sci Sports Exerc. 2013;45:462-469.

29. Tavlo M, Eljaja S, Jensen JT, Siersma VD, Krogsgaard MR. The role of the anterolateral ligament in ACL insufficient and reconstructed knees on rotatory stability: a biomechanical study on human cadavers. Scand J Med Sci Sports. 2016;26:960-966.

30. Van der Watt L, Khan M, Rothrauff BB, Ayeni OR, Musahl V, Getgood A, Peterson D. The structure and function of the anterolateral ligament of the knee: a systematic review. Arthroscopy. 2015;31:569-582.e563.

31. Vincent JP, Magnussen RA, Gezmez F, Uguen A, Jacobi M, Weppe F, Al-Saati MF, Lustig S, Demey G, Servien E, Neyret P. The anterolateral ligament of the human knee: an anatomic and histologic study. Knee Surg Sports Traumatol Arthrosc. 2012;20:147-152. 